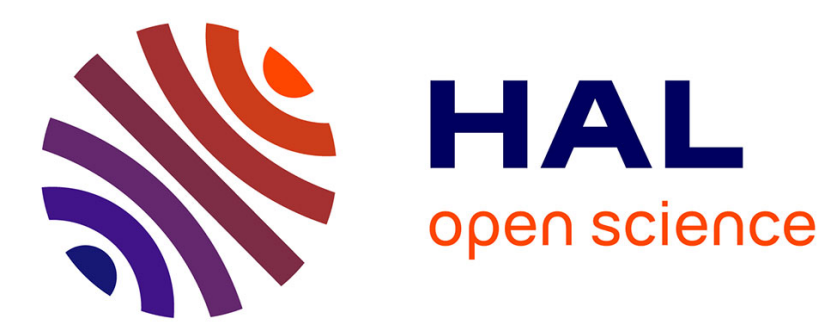

\title{
On the accuracy of equivalent roughness height formulas in practical applications
}

\author{
B. Camenen, M. Larson
}

\section{To cite this version:}

B. Camenen, M. Larson. On the accuracy of equivalent roughness height formulas in practical applications. Journal of Hydraulic Engineering, 2013, 139 (3), p. 331 - p. 335. 10.1061/(ASCE)HY.19437900.0000670. hal-00920719

\section{HAL Id: hal-00920719 \\ https://hal.science/hal-00920719}

Submitted on 19 Dec 2013

HAL is a multi-disciplinary open access archive for the deposit and dissemination of scientific research documents, whether they are published or not. The documents may come from teaching and research institutions in France or abroad, or from public or private research centers.
L'archive ouverte pluridisciplinaire HAL, est destinée au dépôt et à la diffusion de documents scientifiques de niveau recherche, publiés ou non, émanant des établissements d'enseignement et de recherche français ou étrangers, des laboratoires publics ou privés. 


\title{
On the accuracy of equivalent roughness height formulas in practical applications
}

\author{
Benoît Camenen*†and Magnus Larson ${ }^{\ddagger}$
}

\section{Abstract}

2 This paper presents a discussion on the application and accuracy of roughness height formulas from a practical point of view. Such formulas have been

4 proposed to describe the equivalent roughness height for plane bed conditions based on the Shields parameter. The application of these relationships requires an iterative solution technique. However, as this note demonstrates,

7 the roughness estimates are not always reliable since the application of the

formulas yield large discrepancies in the results.

\footnotetext{
* Corresponding author, benoit.camenen@irstea.fr

${ }^{\dagger}$ Irstea, UR HHLY, Hydrology-Hydraulics Research Unit, 3 bis quai Chauveau, CP 220, F-69336 Lyon cedex 09, France

${ }^{\ddagger}$ Dept. of Water Resources Eng., Lund University, Box 118, S-221 00 Lund, Sweden, E-mail: magnus.larson@tvrl.lth.se
} 


\section{Keywords}

Roughness height, friction factor, plane bed, sheet flow, experimental data, predictive formula, iterative formula.

\section{Introduction}

Estimating bedload transport is of great importance for engineering design and morphodynamic modelling; yet bedload transport rate predictions are based on insufficient understanding of the resistance to flow in alluvial channels. Although the roughness height or resistance coefficient are quite difficult to estimate, they remain fundamental parameters in bed shear stress and sediment transport calculations. Total resistance to the flow in a river includes grain resistance, bedform resistance, resistance due to lateral and vertical channel irregularities, as well as dissipation due to the solid transport (Recking et al., 2008). Meyer-Peter and Müller (1948) introduced a linear decomposition of the total resistance coefficient, which may be rewritten as a linear decomposition of the total bed roughness (Soulsby, 1997; Camenen et al., 2006).

Excluding form drag, the value of the equivalent roughness height $k_{s}$ still varies considerably depending on the configuration of the grains forming the bed roughness or the dissipation due to sediment transport. If $k_{s}$ is generally assumed to be proportional to a characteristic bed grain size (Bathurst, 
1985), several authors showed a significant increase in $k_{s}$ when bedload transport occurs, even for coarse sediments (Campbell et al., 2005; Recking et al., 2008). This increase in roughness is often explained for fine sediments by the dissipation of energy in the sheet flow layer that appears for large Shields parameter values (dimensionless bed shear stress defined such as $\theta=R I /\left[(s-1) d_{50}\right]$, with $R$ : hydraulic radius, $I$ : energy slope, $s$ : relative density of the sediment to the fluid, and $d$ : grain size). Sediments move collectively along the bottom mainly in a layer and $k_{s} \approx \delta_{s}$, where $\delta_{s}$ is the thickness of the sheet flow layer (Wilson, 1989). This movement induces an effective roughness ratio $k_{s} / d$, where $d$ is the grain size diameter, up to 50 (Wilson, 1966; Nnadi and Wilson, 1992; Sumer et al., 1996). Based on a large data set, Recking et al. (2008) found a significant difference in the fit of a logarithmic law for the friction coefficient depending on the presence of sediment movement, which can be described in terms of a roughness, such as the $k_{s} / d$-ratio, that varies from approximately 1 for a fixed bed to 3 for a moderate sediment transport rate.

Generally, this phenomenon was expressed using a Shields parameter value $\theta$ over a critical value for the upper plane bed regime, where $k_{s}$ is not only a function of the median grain size $d_{50}$ but also of $\theta$ (Wilson, 1966; Nnadi and Wilson, 1992; Yalin, 1992; van Rijn, 1993; Sumer et al., 1996; Bayram et al., 2003; Camenen et al., 2006) or of bedload transport rate, if the latter is assumed to be directly related to the Shields parameter (Meyer-Peter 
and Müller, 1948). Most of the formulas were validated for fine sediments and high shear stresses. Sumer et al. (1996) observed that the roughness height may be a function of a dimensionless settling velocity $\varpi_{s}=W_{s} / u_{*}$ (where $W_{s}$ is the settling velocity and $u_{*}$ the shear velocity). Camenen et al. (2006) also showed that large values on the effective roughness ratio $k_{s} / d_{50}$ can be observed for lower values of the Shields parameter. They proposed a new relationship for the critical Shields parameter for the upper plane regime, which is a function of a dimensionless settling velocity $W_{s *}=$ $\left[(s-1)^{2} /(g \nu)\right]^{1 / 3} W_{s}$ (where $g$ the acceleration due to gravity, and $\nu$ the kinematic viscosity of the fluid) and a Froude number $F_{r}=U_{c} / \sqrt{g h}$ (where $U_{c}$ the steady current velocity and $h$ the water depth). Then, for a low Froude number and coarse sediment, large effective roughness ratios are also observed. The flow seems to be affected by the bed load transport for these particular cases as much as in the sheet flow transport cases.

However, one important aspect of these previous studies is that all the equations presented in Camenen et al. (2006) have been fitted knowing the total shear stress, since it is directly computed from energy slope measurements. Therefore, in practical applications, as the total Shields parameter is an unknown, these relationships induce an iterative method for the computation of the roughness height and the total Shields parameter. Two main problems may occur: (1) a solution does not always exist depending on the proposed equation (or more than one solution exist), and (2) the 
The iterative solution can be expressed using the relationship for the friction coefficient (see Eq. 12 in Camenen et al., 2006) and the definition of the Shields parameter (see Eq. 2 in Camenen et al., 2006). Assuming the hydraulic radius $R$, median grain size $d_{50}$, relative density of sediments $s$, and depth averaged velocity $U_{c}$ as input parameters, the only unknown parameter to estimate the Shields parameter is the roughness height $k_{s}$ or roughness length $z_{0}=k_{s} / 30$. Thus, the Shields parameter can be expressed 
as a function of $k_{s} / d_{50}$ :

$$
\theta=F\left(\frac{k_{s}}{d_{50}}\right)=\left[\frac{\kappa}{\left(R+z_{0}\right) / R \ln \left(\left(R+z_{0}\right) / z_{0}\right)-1}\right]^{2} \frac{U_{c}^{2}}{(s-1) g d_{50}}
$$

Employing the relationships proposed by different authors (Wilson, 1966; Yalin, 1992; van Rijn, 1993; Sumer et al., 1996; Bayram et al., 2003; Camenen et al., 2006), which can be expressed as $k_{s} / d_{50}=f(\theta)$, equation 1 can easily be solved using an iterative technique. The function $f$ may often be written according to:

$$
\frac{k_{s}}{d_{50}}=f(\theta)=a_{1}+a_{2} \theta^{b}
$$

where $a_{1}, a_{2}$ and $b$ are constants $\left(0 \leq a_{1} \leq 5,1 \leq b \leq 2.5\right.$ and $a_{2}$ varies with $b$ and authors; $b$ can also be a function of the settling velocity, shear velocity or/and the Froude number).

The iterative procedure may be summarized as follows:

- fix a first value for $k_{s}: k_{s, p 1}=\alpha d_{50}(\alpha=2$ may be used assuming skin roughness),

- compute $\theta_{p}$ using Eq. 1 with $k_{s}=k_{s, p 1}$,

- compute a new value for $k_{s}: k_{s, p 2}$ using Eq. 2 with $\theta=\theta_{p}$,

- while $\left|1-k_{s, p 1} / k_{s, p 2}\right|>\epsilon$, fix $k_{s, p 1}=k_{s, p 2}$ and iterate the previous two operations

Of course, the choice of $\alpha$ and $\epsilon(\epsilon=0.01$ was used $)$ may slightly influence the results. 


\section{Graphical interpretation of the iterative procedure}

It is also possible to graphically represent this iterative procedure. Fig. 1 presents curves of the effective roughness ratio plotted against the total Shields parameter obtained from various equations $k_{s} / d_{50}=f(\theta)$ and the equation $k_{s} / d_{50}=F^{-1}(\theta)$ (represents calculation of $k_{s} / d_{50}$ from the total Shields parameter, see Eq. 1) for two particular cases: figure (a) corresponds to an experimental case from Smart (1984); figure (b) corresponds to an experimental case from Nnadi and Wilson (1992).

Fig. 1 here

In Fig. 1, it can be seen that both functions $f(\theta)$ and $F^{-1}(\theta)$ are increasing functions of $\theta$, but $f(\theta)$ is a convex function, whereas $F^{-1}(\theta)$ is a concave function. In general, this means that either two solutions coexist (cf. Fig. 1(a)) or no solution exists (cf. Fig. 1(b) for the Sumer et al. formula). Another observation is that the similar slopes of these curves $(f(\theta)$ and $\left.F^{-1}(\theta)\right)$ close to the intersection points induces large uncertainties $(c f$.

Fig. 1(a) for the formula proposed by Camenen et al. or (b) for all formulas). This effect is not as strong for the Wilson formula since the power on $\theta$ is not as large as for the other equations ( 1 compared to 1.5 or 2.5$)$. The iterative method will never induce a better result compared to the fitted curve because the two curves $f$ and $F^{-1}$ are increasing functions of $\theta$. In Fig. 2 are two different situations presented that illustrates this point: 
1. A slight underestimation is observed using the fitted curve. The experimental point is $E_{1}$ with the coordinates $\left(\theta_{1},\left(k_{s} / d_{50}\right)_{1 e}\right)$. The estimated value of $\left(k_{s} / d_{50}\right)$ from the fitted curve is such that $\left(k_{s} / d_{50}\right)_{1 p}<$ $\left(k_{s} / d_{50}\right)_{1 e}\left(\right.$ point $\left.P_{1}\right)$. From the iterative method (point $\left.I_{1}\right)$, the predicted value of $\theta$ is necessarily smaller $\left(\theta_{1 i}<\theta_{1}\right)$. Thus, $\left(k_{s} / d_{50}\right)_{1 i}<$ $\left(k_{s} / d_{50}\right)_{1 p}<\left(k_{s} / d_{50}\right)_{1 e}$.

2. A slight overestimation is observed using the fitted curve. The experimental point is $E_{2}$ with the coordinates $\left(\theta_{2},\left(k_{s} / d_{50}\right)_{2 e}\right)$. The estimated value of $\left(k_{s} / d_{50}\right)$ from the fitted curve is such that $\left(k_{s} / d_{50}\right)_{2 p}>$ $\left(k_{s} / d_{50}\right)_{2 e}$ (point $\left.P_{2}\right)$. From the iterative method, the predicted value of $\theta$ is necessarily larger $\left(\theta_{2 i}>\theta_{2}\right)$. Thus, $\left(k_{s} / d_{50}\right)_{2 i}>\left(k_{s} / d_{50}\right)_{2 p}>$ $\left(k_{s} / d_{50}\right)_{2 e}$.

Fig. 2 here

In conclusion, it appears that the iterative method is not very accurate from a practical point of view. A solution does not always exist, and most of the time, two solutions coexist. If there is an error between the data and the fitted curve, it will necessarily be larger after employing the iterative method. 


\section{Results obtained from the iterative methods}

\section{Prediction of the roughness height}

In order to discuss the iterative method, several empirical formulas for Eq. 2 presented in Camenen et al. (2006) were tested using the same data set for plane bed conditions also introduced in Camenen et al. (2006). In Table 1 are the predictions of equivalent roughness height within a factor of 2 ( $P 2$ in $\%)$ and $5(P 5$ in \%) of the measured values presented for the different formulas, as well as the mean value $(m r)$ and standard deviation $(s r)$ of the ratio $r=k_{s, \text { pred }} / k_{s, \text { expe }}$. The term "Er $r_{\text {log" }}$ (logarithmic error index, in \%) is defined as,

$$
E r_{\text {log }}=\frac{100}{n} \sum_{1}^{n}\left|\log \left[\frac{\left(k_{s} / d_{50}\right)_{\text {pred }}}{\left(k_{s} / d_{50}\right)_{\text {expe }}}\right]\right|
$$

in which $n$ denotes the number of observations. When no solution existed, a value $k_{s} / d_{50}=250$ (maximum roughness height ratio observed experimentally) was chosen, and when several solutions coexisted, the smallest value was chosen. As a comparison, results using the grain related roughness $\left(k_{s}=2 d_{50}\right)$ and a recently published formula by Rickenmann and Recking (2011) are also presented $\left(U_{c} / u_{*}=4.416\left(R / d_{84}\right)^{1.904}\{1+\right.$ $\left.\left.\left[R /\left(1.283 d_{84}\right)\right]^{1.618}\right\}^{-1.083}\right)$. imental total shear stress values, the iterative solution for a pair $\left(k_{s}, \theta\right)$

Tab. 1 here

Although good agreement is found towards the data using the exper- 
induces large discrepancies in the results. As a matter of fact, the accuracy of the results $(P 2)$ drops with $10 \%$ to $30 \%$ depending on the formula used (cf. table 1 and Fig. 3). A large increase in $E r_{l o g}$ and $s r$ is also observed for all the formulas. It clearly appears that the discrepancy of the iterative methods depends mainly on the value of the coefficient $b$ proposed in each formula $(b=1.0$ for the Wilson formula, $b=2.5$ for the Sumer et al. formula and $b=1.7$ for the Bayram et al. and Camenen et al. formulas). Indeed, the larger the coefficient $b$ is, the closer are the two slopes of the functions $F^{-1}(\theta)$ and $f(\theta)$, and the larger the uncertainties induced by the iterative solution. As a result, the obtained $k_{s} / d_{50}$ values often correspond to the minimum value imposed by the formula (skin roughness). This observation is clearly confirmed by the graphs in Fig. 3. It also explains the relatively better results observed for the Sumer et al. formula since there is a higher minimum value $\left(k_{s} / d_{50}=4.5\right)$ when $\varpi=W_{s} / u_{*} \leq 0.9\left(u_{*}=\sqrt{\tau / \rho}\right.$ is the shear velocity, where $\tau$ is the bottom shear stress and $\rho$ the density of the fluid). In Fig. 3, it appears that the Sumer et al. and Bayram et al. formulas yield unrealistic results corresponding to their minimum value ( 2 or 4.5 for the Sumer et al. formula depending on $\varpi$ ) for most of the cases. If the Camenen et al. formula yields the best result using the measured Shields parameter, the obtained result from the iterative solution is quite poor and it yields large uncertainties. As many of the experimental cases correspond to a roughness height close to the skin roughness height 
$\left(k_{s} \approx 2 d_{50}\right)$, to use the skin roughness height yields nearly as good result as the more complex formulas. The Rickenmann and Recking formula yields slightly better results but very similar as for the skin roughness. No formula gives good predictions for the roughness height when $k_{s}>10 d_{50}$, but the Wilson formula yields much better results than the other formulas. Finally, the Wilson formula (with a minimum value $k_{s} / d_{50}$ ) produces the best results among the studied formulas, although the scatter is significant.

Fig. 3 here

\section{Prediction of the total Shields parameter}

A comparison between the predicted and the observed value of the Shields parameter shows similar results. A quite large discrepancy is observed for the prediction of the total Shields parameter whatever formula used. Even the Wilson formula, which seems to yield slightly better results for the estimation of the roughness height, does not produce any improvement for the estimation of the total Shields parameter. The Wilson, Bayram et al., and Camenen et al. formulas yield overestimations with relatively large dispersion in the predictions. The Sumer et al. formula, since it gives values

for $k_{s} / d_{50}$ between 2 and 5 , presents slightly better results compared to the other formulas. Finally, it appears that using the skin Shields parameter (or the Rickenmann and Recking formula) yields predictions, which are as good as using the other studied formulas, apart for the large values on the 
Shields parameter, which are underestimated.

Tab. 2 here

\section{Conclusions}

Many formulas have been proposed to estimate the roughness height in the case of plane beds. All the previous authors proposed equations assuming that the total Shields parameter is already known. Although these formulas present interesting results for the understanding of the physics, and reveal the main factors governing roughness, they are not applicable from an engineering point the view. The iterative formulas resulting from these equations yields very large scatter in the results. Finally, the use of the skin Shields parameter produces nearly as good results, apart for large values of the total Shields parameter, which are underestimated. There is thus a strong need for a new method to correctly predict the total Shields parameter for the upper regime where the roughness height is no more a function of the grain size only $\left(k_{s} / d_{50}>5\right)$.

\section{Acknowledgments}

This work was in part conducted under the Inlet Modeling System Work Unit of the Coastal Inlets Research Program, U.S. Army Corps of Engineers, and in part (B.C.) under the sponsorship of the Japanese Society for the 
Promotion of Sciences.

\section{${ }_{211}$ Notation}

212

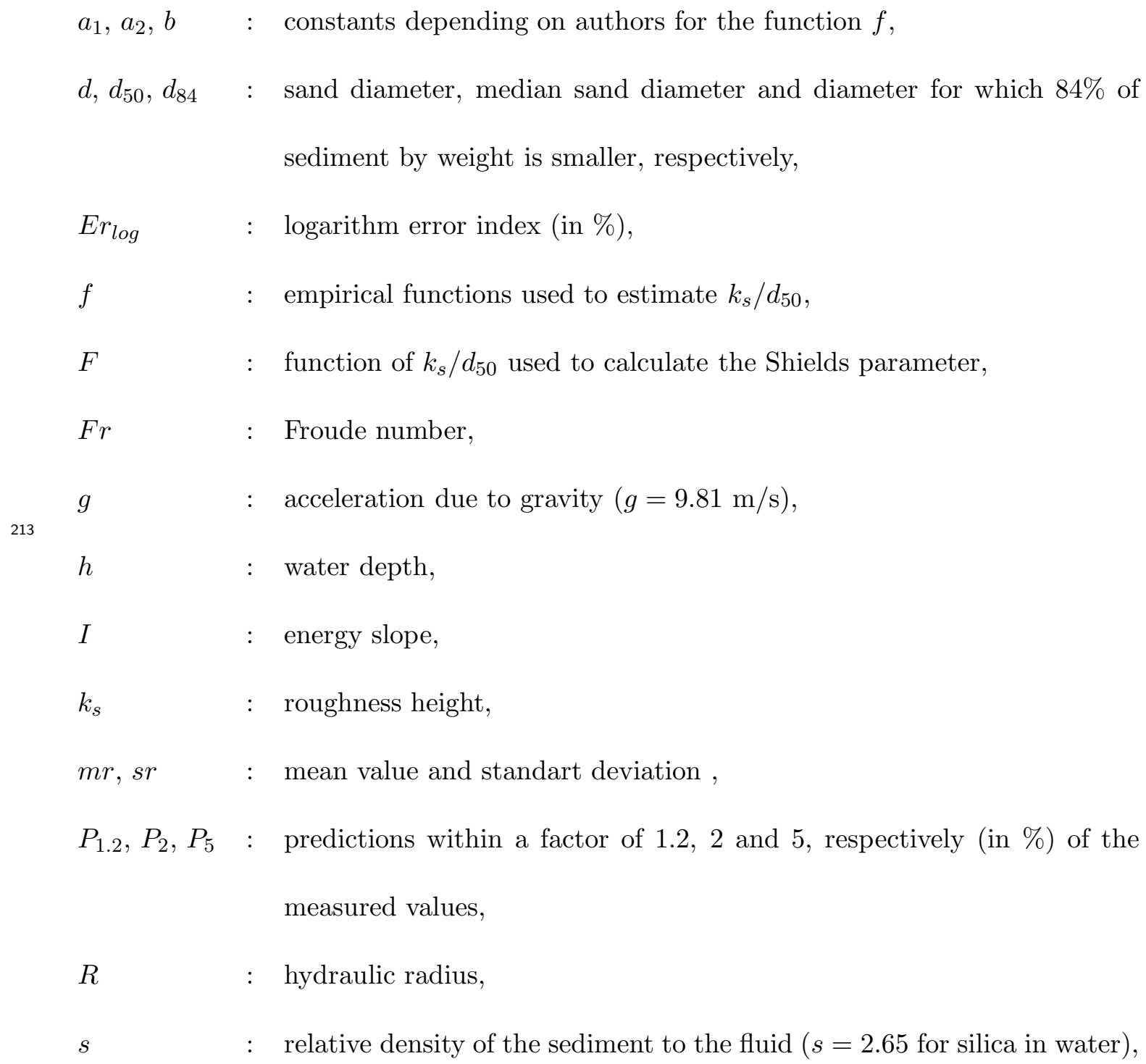




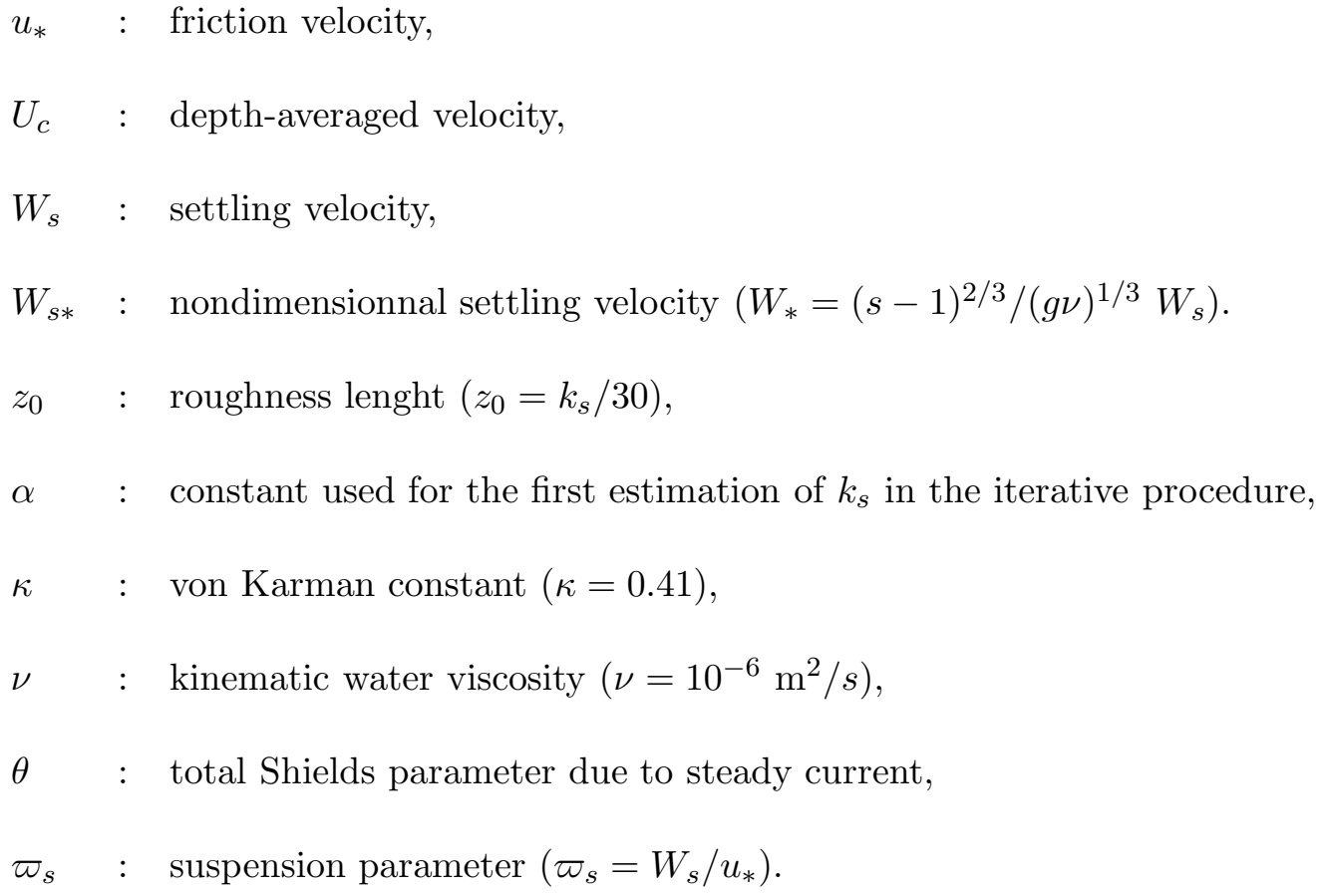

Bathurst, J. C., 1985. Flow resistance estimation in mountain rivers. J. Hydraulic Eng. 111, 625-643.

Bayram, A., Camenen, B., Larson, M., 2003. Equivalent roughness under sheet flow conditions. In: Proc. Coastal Sediments'03. ASCE, Clearwater Beach, Florida, USA, (CD ROM).

Camenen, B., Bayram, A., Larson, M., 2006. Equivalent roughness height for plane bed under steady flow. J. Hydraulic Eng. 132 (11), 1146-1158.

Camenen, B., Larson, M., Bayram, A., 2009. Equivalent roughness height for plane bed under oscillatory flow. Estuarine, Coastal \& Shelf Science 
$81,409-422$.

Campbell, L., McEwan, I., Nikora, V., Pokrajac, D., Gallagher, M., Manes, C., 2005. Bed-load effects on hydrodynamics of rough-bed open-channel flows. J. Hydraulic Eng. 131 (7), 576-585.

Meyer-Peter, E., Müller, R., 1948. Formulas for bed-load transport. In: IInd IAHR Congress. Stockholm, Sweden, pp. 39-64.

Nnadi, F. N., Wilson, K. C., 1992. Motion of contact-load particules at high shear stress. J. Hydraulic Eng. 118 (12), 1670-1684.

Recking, A., Frey, P., Paquier, A., Belleudy, P., Champagne, J. Y., 2008. Feedback between bed load transport and flow resistance in gravel and cobble bed rivers. Water Resources Res. 44 (W05412), 1-21.

Rickenmann, D., Recking, A., 2011. Evaluation of flow resistance in gravel-bed river through a large field data set. Water Resources Res. 47 (W07538), 1-22.

Smart, G. M., 1984. Sediment transport formula for steep channels. J. Hydraulic Eng. 111 (3), 267-276.

Soulsby, R. L., 1997. Dynamics of marine sands, a manual for practical applications. Thomas Telford, London, UK, ISBN 0-7277-2584 X. 
Sumer, B. M., Kozakievicz, A., Fredsœ, J., Deigaard, R., 1996. Velocity and concentration profiles in the sheet-flow layer of movable bed. J. Hydraulic Eng. 122 (10), 549-558.

van Rijn, L. C., 1993. Principles of sediment transport in rivers, estuaries and coastal seas. Aqua Publications, The Netherlands.

Wilson, K. C., 1966. Bed-load transport at high shear stress. J. Hydraulic Division 92 (11), 49-59.

Wilson, K. C., 1989. Mobile bed friction at high shear stress. J. Hydraulic Eng. 115 (6), 825-830.

Yalin, M. S., 1992. River mechanics. Pergamon Press, Oxford. 
Table 1: Prediction of the equivalent roughness height within a factor of 2 and 5 of the measured values together with a logarithmic error index, and the mean value and standard deviation of the ratio $r=k_{s, p r e d} / k_{s, \text { expe }}$ for the studied formulas (R. \& R.: Rickenmann \& Recking) and all data, and data where $\left(k_{s} / d_{50}\right)_{\text {expe }}>10$ (influence of the iterative method on the results).

\begin{tabular}{|c|c|c|c|c|c|c|c|c|c|c|}
\hline \multirow[b]{3}{*}{ Author(s) } & \multicolumn{10}{|c|}{ all data } \\
\hline & \multicolumn{5}{|c|}{ experimental value of $\theta$} & \multicolumn{5}{|c|}{ iterative method } \\
\hline & $P 2$ & $P 5$ & $E r_{l o g}$ & $m r$ & $s r$ & $P 2$ & P5 & $E r_{l o g}$ & $m r$ & $s r$ \\
\hline$k_{s}=2 d_{50}$ & 41 & 73 & 49 & -0.3 & 0.57 & & & - & & \\
\hline R. \& R. & 41 & 81 & 44 & -0.03 & 0.55 & & & - & & \\
\hline Wilson & 57 & 90 & 33 & 0.01 & 0.45 & 44 & 76 & 50 & 0.08 & 0.67 \\
\hline Sumer et al. & 54 & 87 & 34 & -0.09 & 0.50 & 45 & 79 & 46 & -0.09 & 0.62 \\
\hline Bayram et al. & 57 & 88 & 34 & -0.02 & 0.47 & 39 & 74 & 53 & 0.09 & 0.72 \\
\hline \multirow[t]{3}{*}{ Camenen et al. } & 74 & 97 & 23 & -0.01 & 0.30 & 36 & 66 & 61 & -0.01 & 0.81 \\
\hline & \multicolumn{10}{|c|}{ data where $\left(k_{s} / d_{50}\right)_{\text {expe }}>10$} \\
\hline & \multicolumn{5}{|c|}{ experimental value of $\theta$} & \multicolumn{5}{|c|}{ iterative method } \\
\hline Author(s) & $P 2$ & $P 5$ & $E r_{l o g}$ & $m r$ & $s r$ & $P 2$ & $P 5$ & $E r_{l o g}$ & $m r$ & $s r$ \\
\hline$k_{s}=2 d_{50}$ & 0 & 0 & 120 & -1.2 & 0.23 & & & - & & \\
\hline R. \& R. & 0 & 2 & 80 & -0.8 & 0.25 & & & - & & \\
\hline Wilson & 52 & 70 & 47 & -0.4 & 0.55 & 33 & 53 & 69 & -0.5 & 0.71 \\
\hline Sumer et al. & 29 & 60 & 64 & -0.6 & 0.57 & 4 & 36 & 85 & -0.8 & 0.57 \\
\hline Bayram et al. & 46 & 67 & 52 & -0.5 & 0.54 & 9 & 31 & 91 & -0.4 & 0.54 \\
\hline Camenen et al. & 68 & 96 & 27 & -0.2 & 0.29 & 11 & 30 & 93 & -0.6 & 0.83 \\
\hline
\end{tabular}


Table 2: Prediction of total Shields parameter within a factor of 1.2 and 2 of the measured values together with a logarithmic error index, and the mean value and standard deviation of the ratio $r=\theta_{\text {pred }} / \theta_{\text {expe }}$ for the studied formulas (and the skin Shields parameter, as well as the Rickenmann \& Recking formula) and all data.

\begin{tabular}{l|ccccc}
\hline Author(s) & $P 1.2$ & $P 2$ & $E r_{l o g}$ & $m r$ & $s r$ \\
\hline skin Shields parameter & 30 & 75 & 22 & -0.14 & 0.28 \\
Rickenmann \& Recking & 28 & 80 & 20 & -0.04 & 0.27 \\
Wilson & 31 & 75 & 31 & 0.08 & 0.68 \\
Sumer et al. & 32 & 78 & 27 & -0.01 & 0.59 \\
Bayram et al. & 30 & 73 & 38 & 0.14 & 0.77 \\
Camenen et al. & 27 & 67 & 41 & 0.07 & 0.83 \\
\hline
\end{tabular}




\section{(a) (b)}

Fig. 1a Fig. 1b

Figure 1: Graphical illustration of the iterative method for two specific cases

(experimental data from Smart (a) and Nnadi \& Wilson (b)).

Figure 2: Graphical illustration of the iterative method for the two main situations.

experimental value of $\theta$ iterative method
(a)
Fig. 3a1
Fig. $3 \mathrm{a} 2$
(b)
Fig. 3b1
Fig. 3b2
(c)
Fig. 3c1
Fig. 3c2

Figure 3: Effect on the results using an iterative method for the Wilson (a) (with a minimum value of $k_{s} / d_{50}=2$ ), Sumer et al. (b), and Camenen et al. (c) formulas. 


\section{${ }_{253}$ List of Figures}

254 1 Graphical illustration of the iterative method for two specific cases (experimental data from Smart (a) and Nnadi \& Wilson

2 Graphical illustration of the iterative method for the two main situations. . . . . . . . . . . . . . . 19

3 Effect on the results using an iterative method for the Wilson (a) (with a minimum value of $k_{s} / d_{50}=2$ ), Sumer et al. (b), and Camenen et al. (c) formulas. . . . . . . . . . . . . 19 


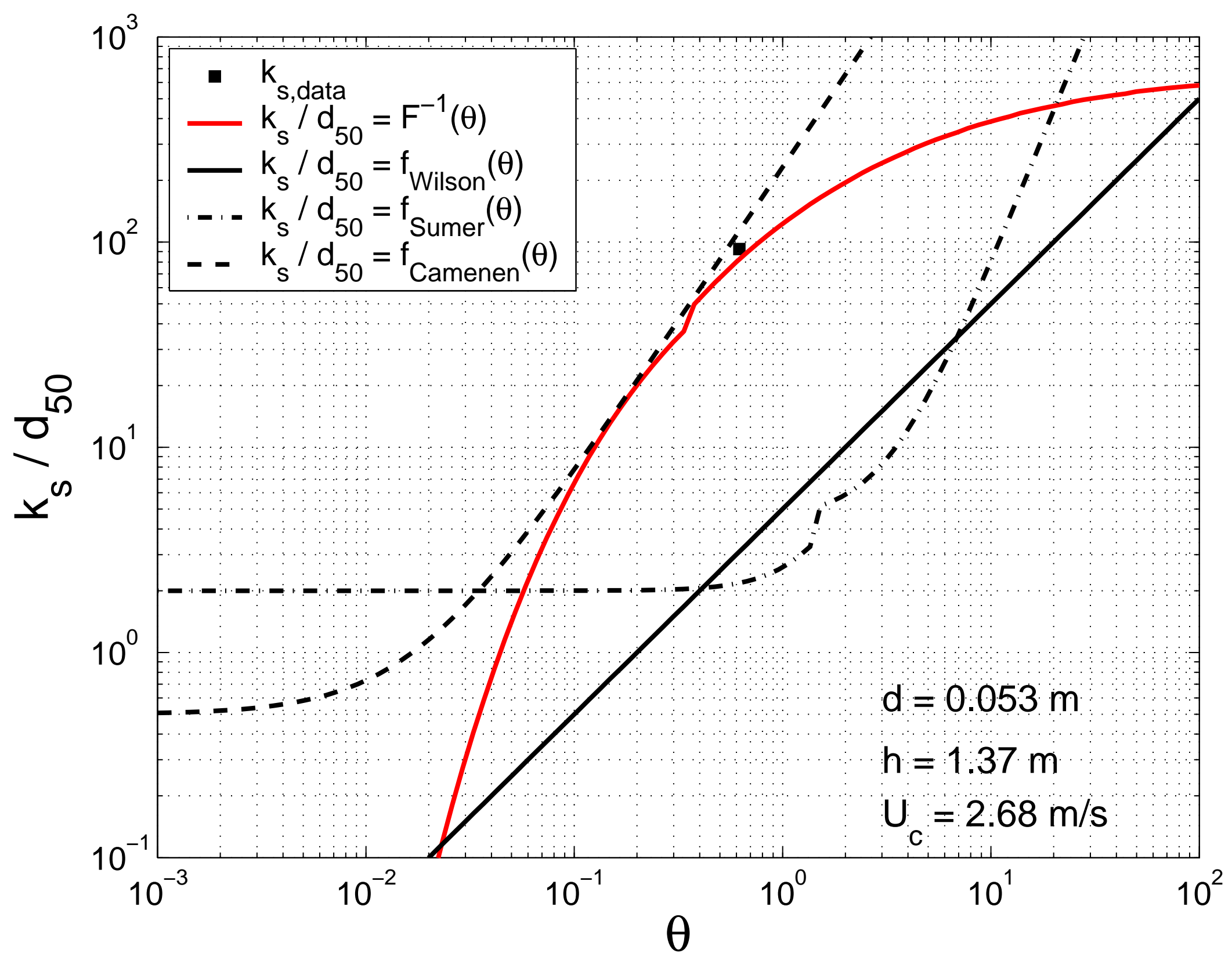




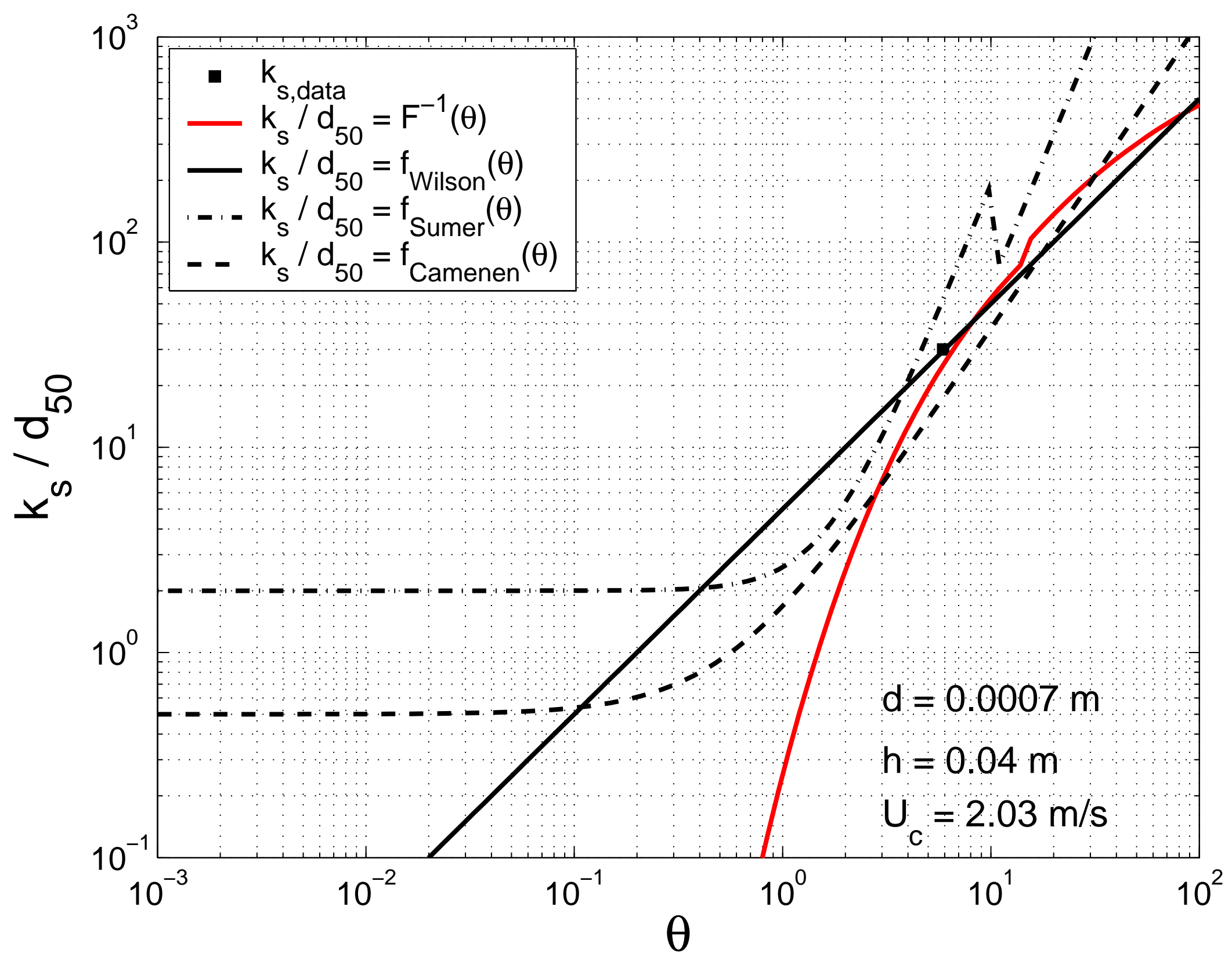




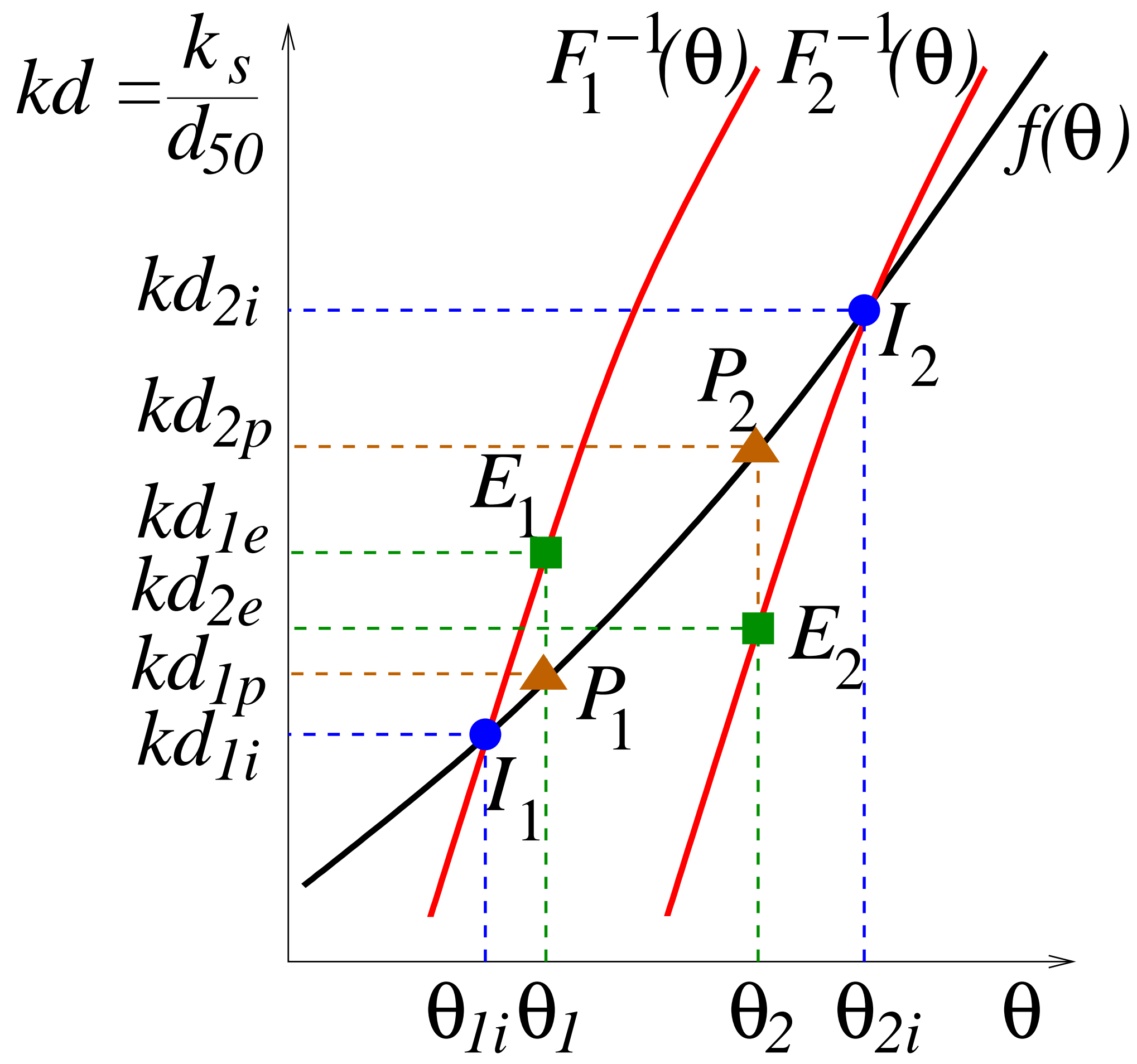




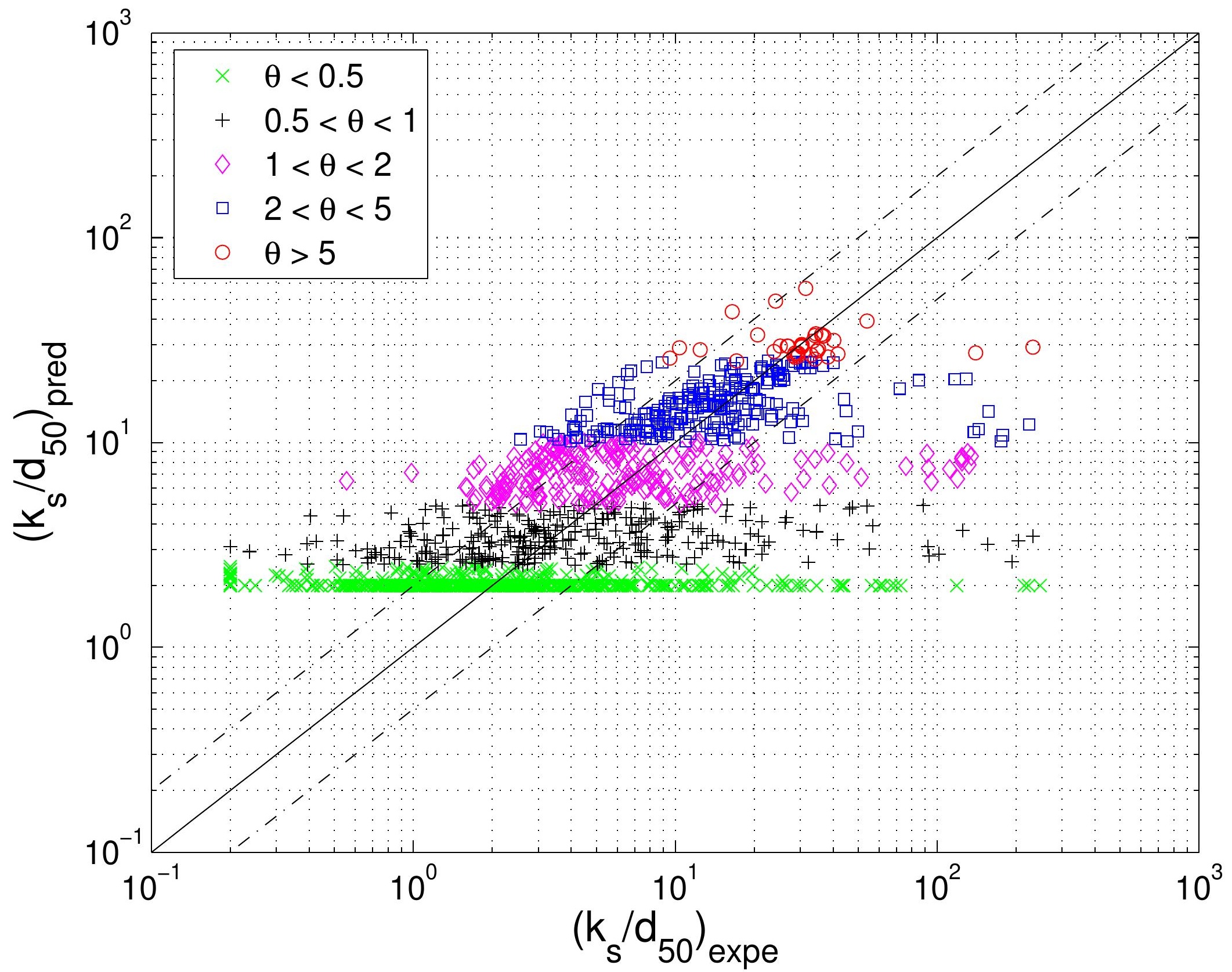


Fig. $3 a 2$

Author-produced version of the article published in J. Hydraul. Eng. (2013), 139(3), 331-335.

Click here to download Figure: ksd5Gindelbitigheatqu(Apsation is available at http://ascelibrary.org DOI : 10.1061/(ASCE)HY.1943-7900.0000670

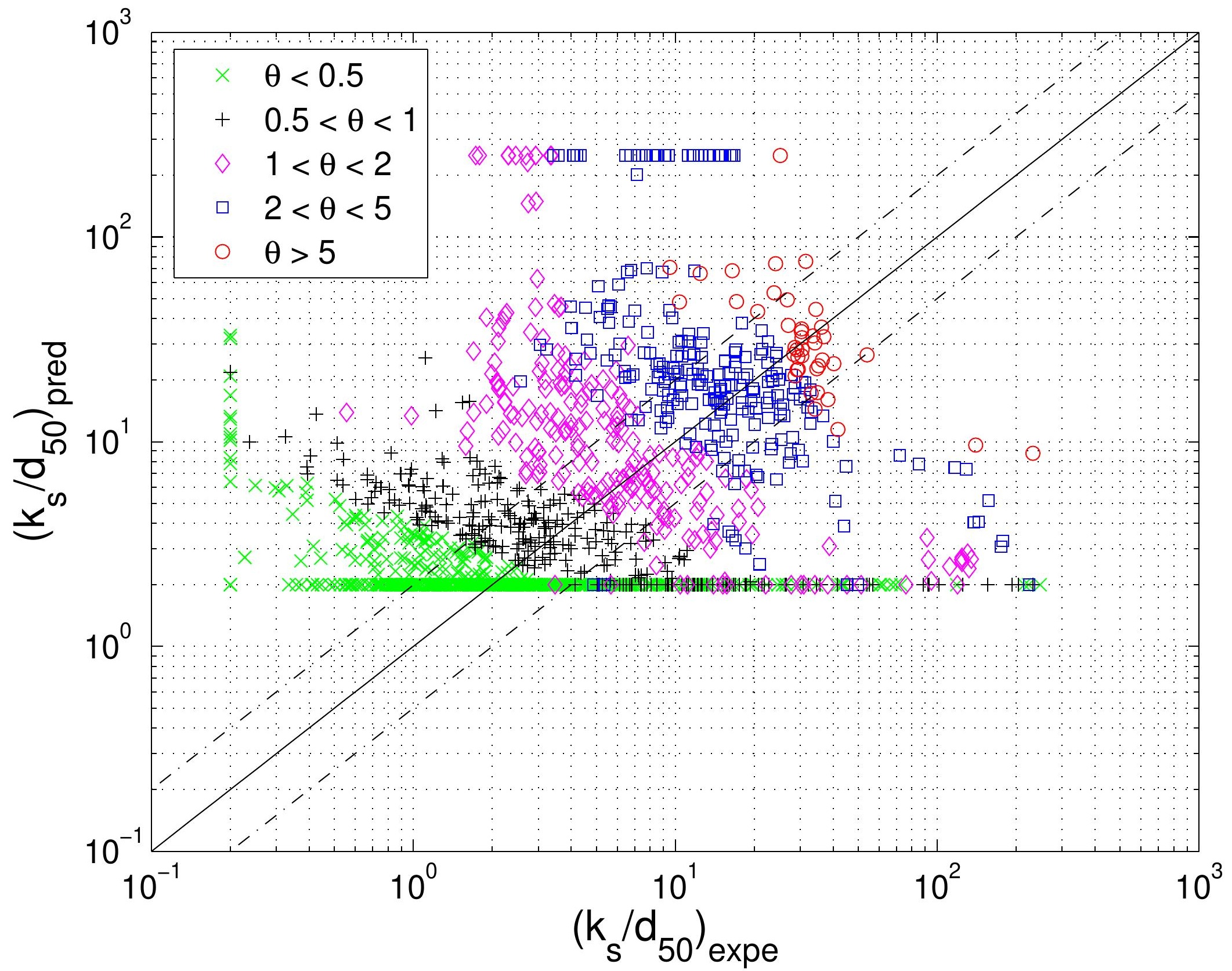




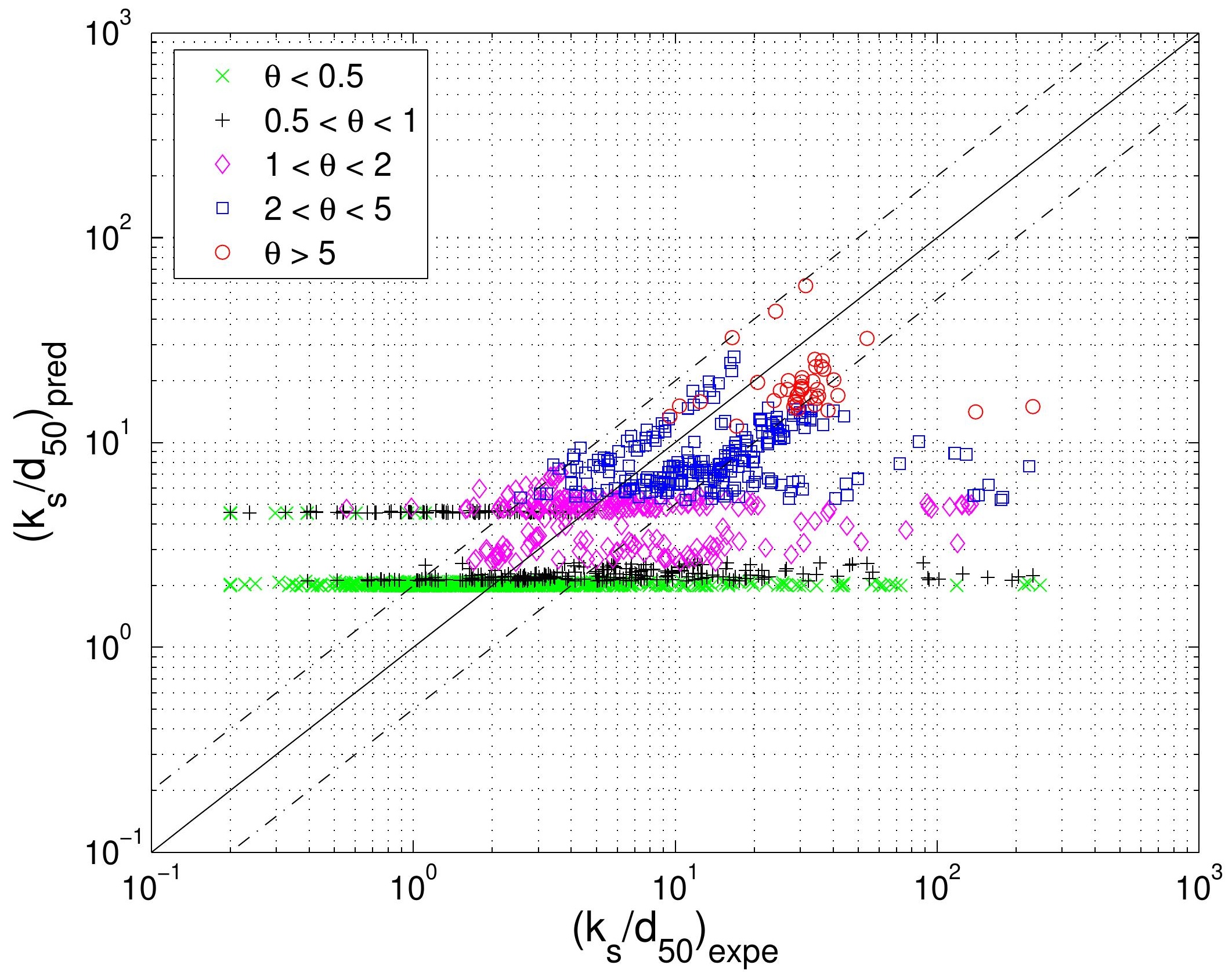




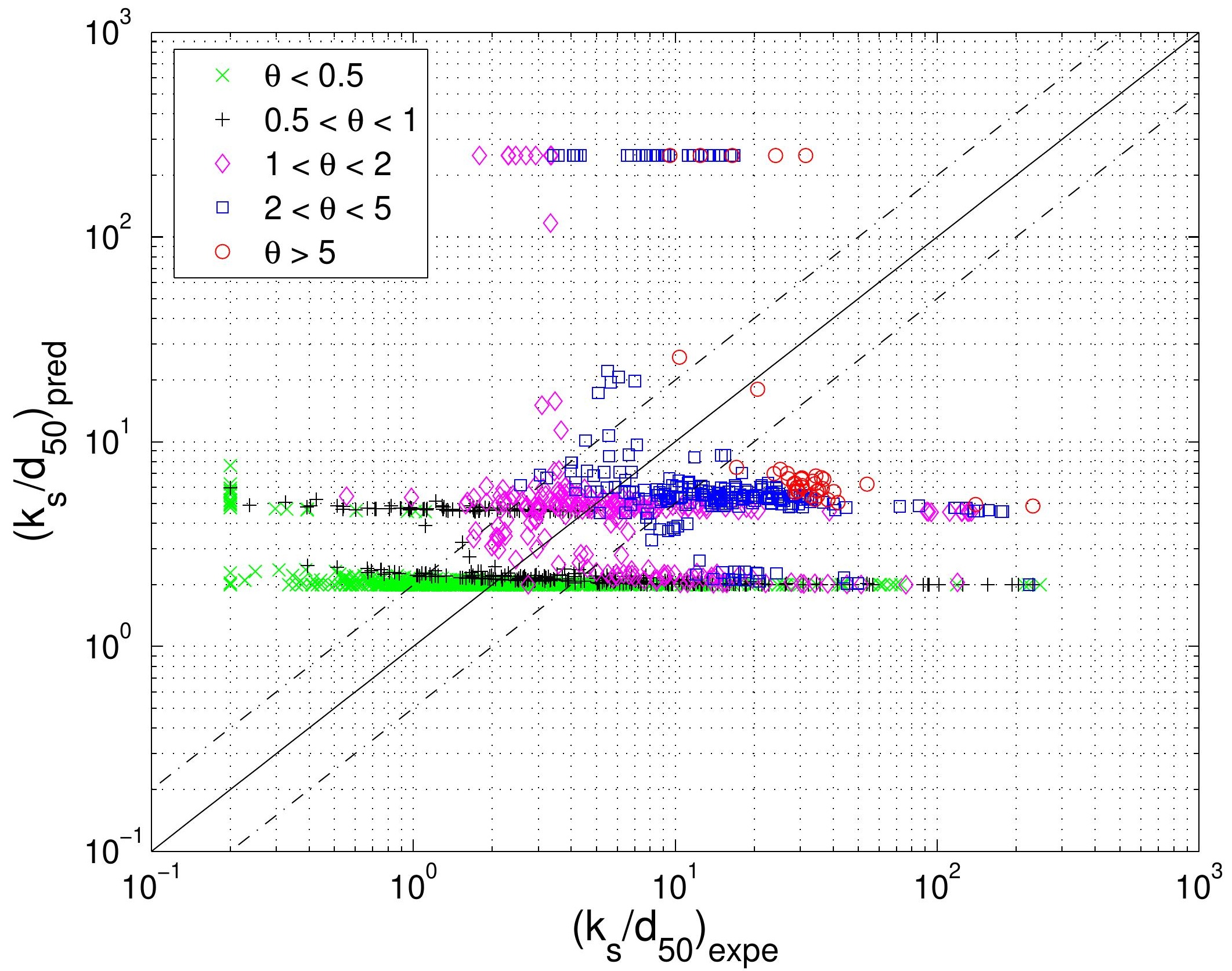




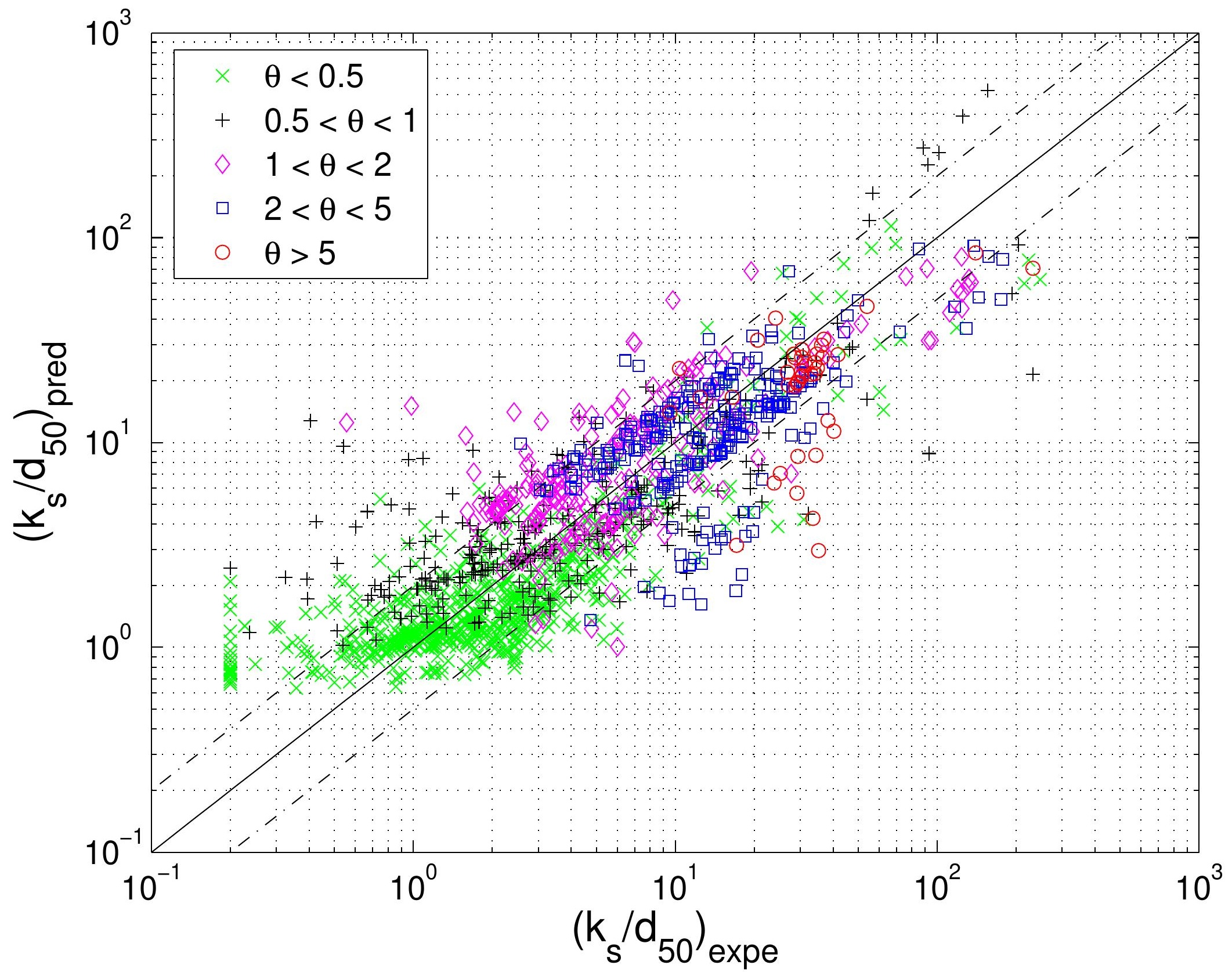


Fig. $3 c 2$

Author-produced version of the article published in J. Hydraul. Eng. (2013), 139(3), 331-335.

Click here to download Figure: ksd5QihEBilgitian\$aborsion is available at http://ascelibrary.org DOI : 10.1061/(ASCE)HY.1943-7900.0000670

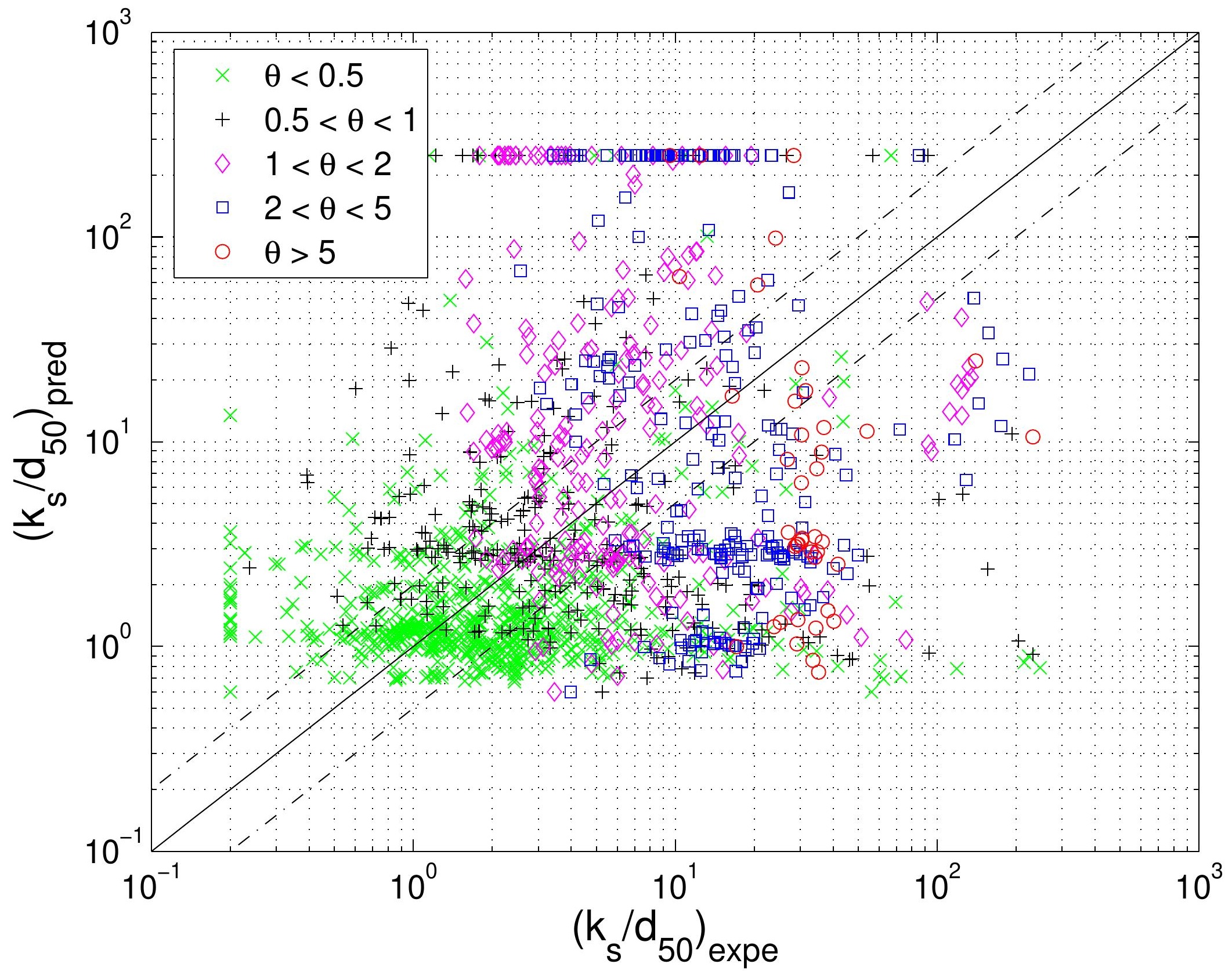


${ }^{*}$ Copyright Agreement

Author-produced version of the article published in J. Hydraul. Eng. (2013), 139(3), 331-335.

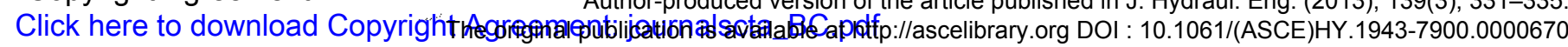

ASGE

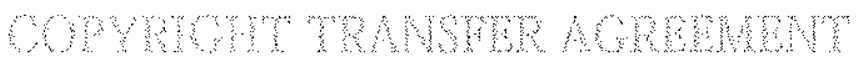

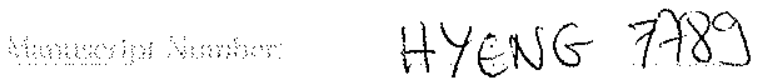

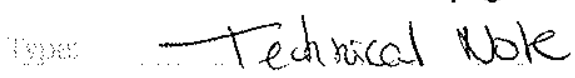

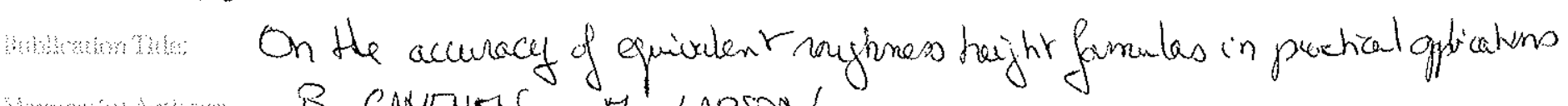

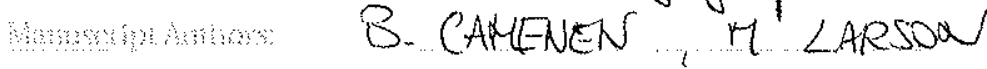

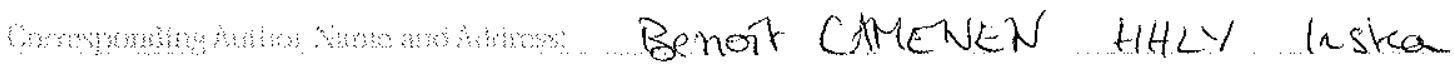
3. bis yoi Chaveon CP220 F-69336 Lyon ledew o9

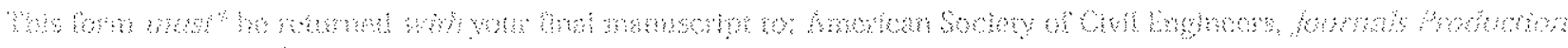

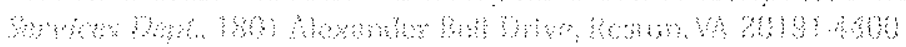

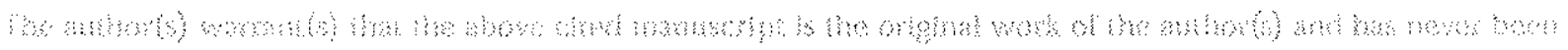

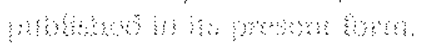

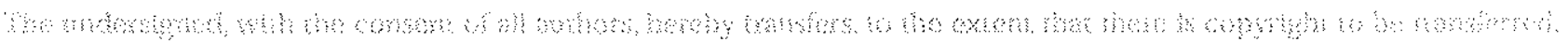

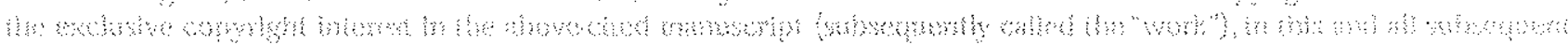

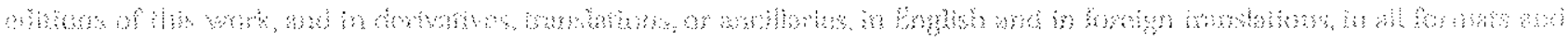

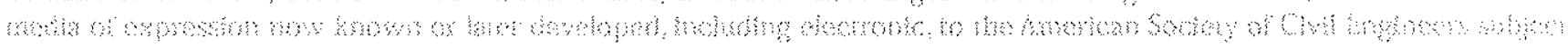

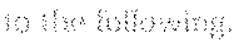

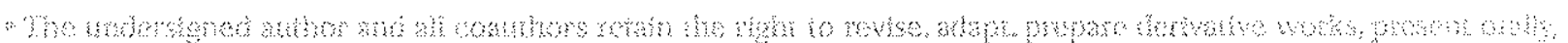

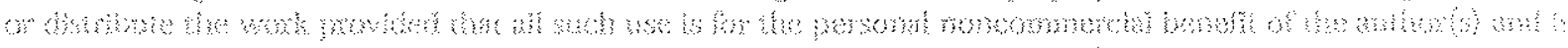

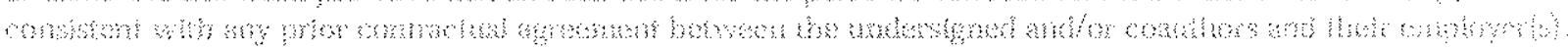

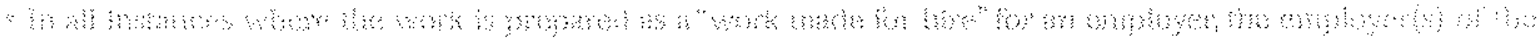

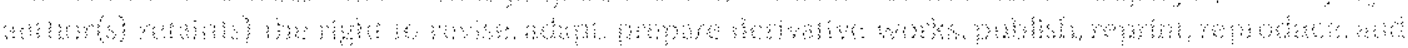
Aento moman: an

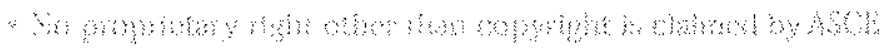

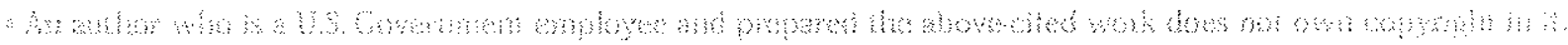

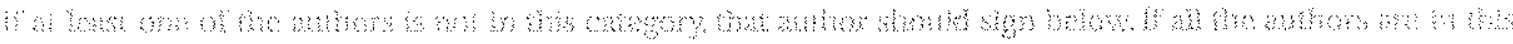
warks now

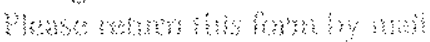

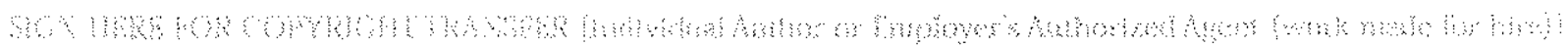

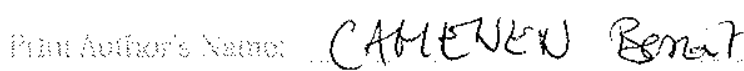

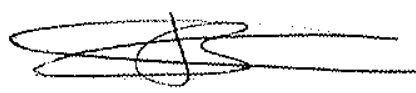

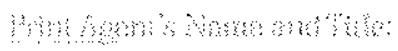

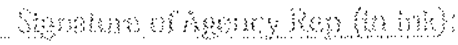

ath Deanber goll

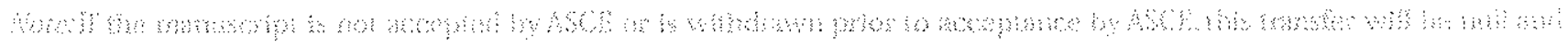

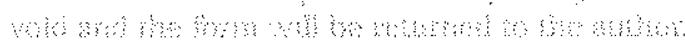

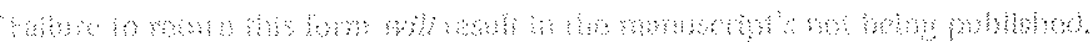


Note: The worksheet is designed to automatically calculate the total number of printed pages when published in ASCE $t$ format.

\begin{tabular}{|l}
\hline Journal Name: \\
\hline Author Full Name: \\
\hline
\end{tabular}

|| Manuscript \# (if known): Author Email:

The maximum length of a technical paper is 10,000 words and word-equivalents or 8 printed pages. A technical note should not exceed 3,50( word-equivalents in length or 4 printed pages. Approximate the length by using the form below to calculate the total number of words in the $t$ adding it to the total number of word-equivalents of the figures and tables to obtain a grand total of words for the paper/note to fit ASCE form Overlength papers must be approved by the editor; however, valuable overlength contributions are not intended to be discouraged by this proc

\section{Estimating Length of Text}

A. Fill in the four numbers (highlighted in green) in the column to the right to obtain the total length of text.

NOTE: Equations take up a lot of space. Most computer programs don't count the amount of space around display equations. Plan on counting 3 lines of text for every simple equation (single line) and 5 lines for every complicated equation (numerator and denominator).

\section{Estimating Length of Tables}

A. First count the longest line in each column across adding two characters between each column and one character between each word to obtain total characters.

1-column table $=$ up to 60 characters wide $\quad$ 2-column table $=61$ to 120 characters wide

B. Then count the number of text lines (include footnote $\&$ titles)

1-column table $=$ up to 60 characters wide by:

17 lines (or less) $=158$ word equiv. up to 34 lines $=315$ word equiv. up to 51 lines $=473$ word equiv. up to 68 text lines $=630$ word equiv. 2-column table $=61$ to 120 characters wide by:

17 lines (or less) $=315$ word equiv. up to 34 lines $=630$ word equiv. up to 51 lines $=945$ word equiv. up to 68 text lines $=1260$ word equiv.

C. Total Characters wide by Total Text lines = word equiv. as shown in the table above. Add word equivalents for each table in the column labeled "Word Equivalents."

\section{Estimating Length of Figures}

A. First reduce the figures to final size for publication.

Figure type size can't be smaller than 6 point $(2 \mathrm{~mm})$.

B. Use ruler and measure figure to fit 1 or 2 column wide format.

1-column fig. = up to 3.5 in. $(88.9 \mathrm{~mm}) \quad$ 2-col. fig. $=3.5$ to 7 in. $(88.9$ to $177.8 \mathrm{~mm}$ ) wide

C. Then use a ruler to check the height of each figure (including title \& caption).

1-column fig. = up to 3.5 in. $(88.9 \mathrm{~mm})$ wide by:

up to 2.5 in. $(63.5 \mathrm{~mm})$ high $=158$ word equiv. up to 5 in. $(127 \mathrm{~mm})$ high $=315$ word equiv. up to 7 in. $(177.8 \mathrm{~mm})$ high $=473$ word equiv. up to 9 in. $(228.6 \mathrm{~mm})$ high $=630$ word equiv.

D. Total Characters wide by Total Text lines = word equiv. as shown in the table above. Add word equivalents for each table in the column labeled "Word Equivalents."

\begin{tabular}{|r|r|}
\hline Total Tables/Figures: & 1421 \\
\hline Total Words of Text: & 3059 \\
\hline
\end{tabular}

Total words and word equivalents: 4480 printed pages: (word equivalents)

\begin{tabular}{|c|r|}
\hline \multicolumn{2}{|c|}{ Estimating Length of Text } \\
\hline $\begin{array}{c}\text { Count \# of words in 3 } \\
\text { lines of text: }\end{array}$ \\
\hline Divided by 3 & 35 \\
\hline Average \# of words per line & 3 \\
\hline $\begin{array}{c}\text { Count \# of text } \\
\text { lines per page }\end{array}$ \\
\hline \# of words per page & 18 \\
\hline $\begin{array}{c}\text { Count \# of pages (don't } \\
\text { add references \& } \\
\text { abstract) }\end{array}$ & 210.00 \\
\hline Title \& Abstract & 11 \\
\hline \multirow{2}{*}{ Total \# refs } & 500 \\
\hline Length of Text is & 0 \\
\hline \multicolumn{2}{c}{} \\
\cline { 2 - 3 }
\end{tabular}

\begin{tabular}{|c|c|c|}
\hline \multicolumn{3}{|c|}{ Estimating Length of Tables \& } \\
\hline Tables & $\begin{array}{c}\text { Word } \\
\text { Equivalents }\end{array}$ & Figures \\
\hline Table 11 & 317 & Figure 1 \\
\hline 2 & 158 & 2 \\
\hline 3 & 0 & 3 \\
\hline 4 & 0 & 4 \\
\hline$\overline{5}$ & 0 & 5 \\
\hline 6 & 0 & 6 \\
\hline 7 & 0 & 7 \\
\hline 8 & 0 & 8 \\
\hline 9 & 0 & 9 \\
\hline 10 & 0 & 10 \\
\hline 11 & 0 & 11 \\
\hline 12 & 0 & 12 \\
\hline 13 & 0 & 13 \\
\hline 14 & 0 & 14 \\
\hline 15 & $\overline{0}$ & 15 \\
\hline \multirow{5}{*}{\multicolumn{2}{|c|}{$\begin{array}{l}\text { Please double-up } \\
\text { tables/figures if } \\
\text { additional space is } \\
\text { needed (ex. 20+21). }\end{array}$}} & 16 \\
\hline & & 17 \\
\hline & & 18 \\
\hline & & 19 \\
\hline & & 20 and 21 \\
\hline
\end{tabular}




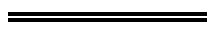

\section{wo-column}

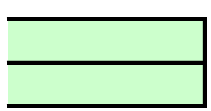

J words and

ext and

lat.

:edure.

subtototal

plus headings

TOTAL words

printed pages

\begin{tabular}{r|}
\multicolumn{1}{c|}{ Figures: } \\
\hline \multicolumn{1}{c|}{$\begin{array}{l}\text { Word } \\
\text { Equivalents }\end{array}$} \\
\hline \hline 158 \\
\hline 158 \\
\hline 630 \\
\hline 0 \\
\hline 0 \\
\hline 0 \\
\hline 0 \\
\hline 0 \\
\hline 0 \\
\hline 0 \\
\hline 0 \\
\hline 0 \\
\hline 0 \\
\hline 0 \\
\hline 0 \\
\hline 0 \\
\hline 0 \\
\hline 0 \\
\hline 0 \\
\hline 0 \\
\hline
\end{tabular}


Ref.: Ms. No. HYENG-7789

"On the application of the equivalent roughness height formulas" by Benoit Camenen \& Magnus Larson

Answer to the last request by editor and associate editor

A copy of a double-spaced list of figure captions is provided on a separate page latex format as requested. The presentation of the figure disposition and caption is still kept (previous page) in order to better understand the link between eps files provided and figures. 